\title{
The Maugeri daily activity profile: a tool to assess physical activity in patients with chronic obstructive pulmonary disease
}

\author{
Elisabetta Zampogna1, Giorgio Bertolotti ${ }^{1}$, Nicolino Ambrosino², Giuseppe Lo Bello ${ }^{1}$, \\ Francesca Cherubino ${ }^{1}$, Alessandra Ianni ${ }^{1}$, Mara Paneroni ${ }^{3}$, Patrizia Pignatti ${ }^{4}$, Dina Visca ${ }^{1,5}$, \\ Andrea Zanini ${ }^{6}$, Andrea Giordano ${ }^{7}$
}

${ }^{1}$ Respiratory Rehabilitation, ICS Maugeri IRCCS, Institute of Tradate, Italy; ${ }^{2}$ Respiratory Rehabilitation, ICS Maugeri IRCCS, Institute of Montescano, Italy; ${ }^{3}$ Respiratory Rehabilitation, ICS Maugeri IRCCS, Institute of Lumezzane, Italy; ${ }^{4}$ Allergy and Immunology Unit, ICS Maugeri IRCCS, Pavia, Italy; ${ }^{5}$ Department of Medicine and Surgery, Respiratory Diseases, University of Insubria, Varese-Como, Italy; ${ }^{6}$ Ente Ospedaliero Cantonale, Novaggio, Switzerland; ${ }^{7}$ Respiratory Rehabilitation, ICS Maugeri IRCCS, Institute of Veruno, Italy

\begin{abstract}
Patients with chronic obstructive pulmonary disease (COPD) report reduced physical activity (PA). There are only few tools available to assess PA and sedentary behavior in these patients,
\end{abstract}

Correspondence: Elisabetta Zampogna, Respiratory Rehabilitation, ICS Maugeri IRCCS, via Roncaccio 16, 21049 Tradate (VA), Italy. Tel. +39.0331.829596.

E-mail: elisabetta.zampogna@icsmaugeri.it

Authors' contributions: EZ, conception and design, interpretation of data, drafting the manuscript and revising it critically for important intellectual content, final approval; GB, conception and design, interpretation of data; NA, manuscript drafting and revision, data interpretation; GLB, FC, AI, PP, conception and design, data acquisition; MP, data interpretation, critical revision; DV, manuscript drafting, critical revision; AZ, conception, design, data interpretation; AG, conception and analysis, final approval. All the authors have read and approved the final version of the manuscript and agreed to be accountable for all aspects of the work.

Conflict of interest: The authors declare no potential conflict of interest.

Ethical approval: The ICS Maugeri Ethics Committee approved the study protocol (2067 CE, September 26, 2016).

Informed consent: Informed consent was obtained from all subjects.

Availability of data and materials: All data generated or analyzed during this study are included in this published article.

Key words: Chronic respiratory diseases; physical activity; rehabilitation.

Received for publication: 21 November 2020.

Accepted for publication: 22 March 2021.

${ }^{\circ}$ Copyright: the Author(s), 2021

Licensee PAGEPress, Italy

Monaldi Archives for Chest Disease 2021; 91:1680

doi: 10.4081/monaldi.2021.1680

This article is distributed under the terms of the Creative Commons Attribution Noncommercial License (by-nc 4.0) which permits any noncommercial use, distribution, and reproduction in any medium, provided the original author(s) and source are credited. and none of them aims to differentiate between sedentary and active patterns. The aim of the study was to evaluate an easy tool to profile daily activity time in a cohort of patients with COPD, compared to healthy subjects; the study was set at the Istituti Clinici Scientifici Maugeri (ICS), IRCCS of Tradate and Lumezzane, Italy, and at the Ente Ospedaliero Cantonale, Novaggio, Switzerland (Italian Speaking). The populations were inpatients with COPD, healthy subjects. The items of the Maugeri Daily Activity (MaDA) profile were chosen based on literature, interviews with patients and health professionals. Time spent during sleep (ST), when awake (AT), active (ACT) or in sedentary behavior (SET) were recorded. Lung function tests, arterial blood gases, the modified Medical Research Council (mMRC), the six-minute walking distance test (6MWD), the COPD Assessment Test (CAT), and the body-mass index, airflow obstruction, dyspnea, and exercise capacity (BODE) index were also assessed in patients. Sixty patients with COPD and 60 healthy controls filled in the questionnaire. As compared to controls, patients showed longer AT and SET. Active time of patients was significantly cor-related with mMRC, CAT, Bode Index and 6MWD, but not with demographics, anthropometrics or stages of disease. Using this tool, we found that patients with COPD spent longer time awake and in sedentary behavior. The MaDA may be useful to evaluate PA in patients with COPD.

\section{Introduction}

Physical activity (PA), defined as any body movement produced by skeletal muscles resulting in energy expenditure, is characterized by type, intensity, duration, patterns and symptoms experience. It includes, but is not limited to, exercise, leisuretime, domestic and occupational activities $[1,2]$. It has been calculated that elimination of physical inactivity would avoid between 6 and $10 \%$ of the major non communicable diseases, coronary heart disease, type 2 diabetes, breast and colon cancers, and increase life expectancy, whereas higher levels of PA increase healthy and chronic disease-free years $[3,4]$. Daily PA of patients with chronic obstructive pulmonary disease (COPD) is reduced in the early phases of disease as compared to healthy age-matched controls and worsen over time, with important clinical consequences [5].

Pulmonary rehabilitation (PR) that is a comprehensive inter- 
vention to improve the physical and psychological condition of people with chronic respiratory disease and to promote the longterm adherence to health enhancing behaviors [6], sought strategies to improve PA in COPD [7]. It has been speculated that increases in exercise capacity in combination with behavioral changes may also have the potential to increase physical activity in patients with COPD, however so far the studies have yielded inconsistent results [8].

Several methods are able to measure the amount of PA (i.e. metabolic rate, number of daily footsteps) [2]. These instrumental assessments require dedicated equipment which provide different information. Some of those are inexpensive and easy to use. Today, they are not regularly used to evaluate the usual PA of COPD subjects. A profiling tool, able to differentiate sedentary or active patterns, could allow to acquire useful information to identify and customize the optimal components of the rehabilitation (i.e. provide an educational intervention aimed at the subject's habits and not hypothetical-usual habits) [9]. The aim of this study was to evaluate a tool to profile daily activity time in a cohort of COPD patients, compared to healthy subjects.

\section{Methods}

The study was carried out at the ICS Maugeri IRCCS, Institutes of Tradate and Lumezzane, Italy, and at the Ente Ospedaliero Cantonale (Italian speaking), Novaggio, Switzerland. The ICS Maugeri Ethics Committee approved the study protocol (2067 CE, September 26, 2016). Informed consent was obtained from all subjects.

\section{Construction of MaDA}

The active and sedentary activities were administered according a prespecified checklist. The MaDA profile was designed according to the Taxonomy of self-reported sedentary behavior tools (TASST) framework [10]. According to TASST four domains were included: $i$-type of assessment: self-reported; $i i$-recall period: the last week preceding the interview; iii-temporal unit: hour; $i v$ assessment period: week. MaDA construction was performed following two steps:

- Items selection. Preliminary items were chosen based on available literature [11-13]. A team of experts including pulmonologists (DV, AZ, AS), a bioengineer (AG), respiratory therapists (EZ, MP, GLB), a psychologist (GB) and a psychometrist (AI) defined the instructions to administer the pilot version. Subjects had to recall how a specific activity (i.e. gardening) and/or a sedentary behavior (i.e. watching television) was frequent (number of times in a week) and for how long (hours) on average in the week preceding the interview, without any distinction between week and weekend days.

- Revision. In June 2018, 10 patients were administered a preliminary version, afterwards the focus group gave comments, and discussed the relevance and comprehensiveness of the items according to the consensus-based standards for the selection of health measurements instruments (COSMIN) checklist [14]. Some items were reworded when unclear or removed if not relevant. The resulting items were included into the final version. The final version of MaDA assesses the time spent during sleep (average numbers of hours per day), the sedentary activities (such as reading, watching television or using computer, sitting on a public transport: 14 items) and motion activities (such as home works, walking or cycling, leisure time: 10 items). The final version was submitted face to face, individu- ally by trained staff and checked for completeness by the psychometrist. The full English and Italian versions of the MaDA profiler are available as Supplementary Materials.

\section{Participants}

All patients with COPD admitted since October to December 2018 to undergo pulmonary rehabilitation were consecutively recruited. The Maugeri Daily Activity profile (MaDA) was administered within two days since admission. Patients were eligible for inclusion if they fulfilled the following criteria: i) diagnosis of COPD (post-bronchodilator forced expiratory volume in $1 \mathrm{~s}$ $\left(\mathrm{FEV}_{1}\right)$ /forced vital capacity $\left.(\mathrm{FVC})<0.7\right)[14]$; ii) age $\geq 65$ years; iii) Italian speaking; iv) smoking history $\geq 10$ pack/years; v) clinical stability ( $\mathrm{pH}$ range: 7.38 - 7.42, without any change in respiratory medications in the previous 7 days); vi) ability to perform the six-minute walking distance test (6MWD); vii) ability to sign the informed consent.

Exclusion criteria were: other concomitant pulmonary diseases, hospitalization in the 30 days prior enrollment, being on long term oxygen therapy and/or home mechanical ventilation $[15,16]$, any diagnosis of neurological or neuromuscular diseases and any other condition limiting ambulation, memory or comprehension problems.

Control healthy adults of comparable age and gender distribution underwent the administration of the MaDA.

\section{Scoring method}

In order to compute the profile, according to TASST, the duration in hours of the assessment period (one week $=\mathrm{WH}$ ) was divided in sleep (ST) and awake time (AT), with the latter subdivided in active (ACT), sedentary time (SET) and time spent in other or unreported activities (OTH) as shown on Figure 1. Sleep time was obtained by multiplying the reported average daily sleep duration in hours by 7 . Awake time was calculated by adding up time the patient declared to spend in ACT, SET and OTH. Activity time and SET were easily calculated by multiplying the frequency (number of times in a week) for the duration (hours) of the time spent for each item investigated and then summing the results. OTH was a calculated measure and represents the weekly time spent in very short activities, in transitions from a behavior to another one, in activities not included in MaDA or time incorrectly reported due to rounding effects: $\mathrm{OTH}=\mathrm{WH}-(\mathrm{ST}+\mathrm{SET}+\mathrm{ACT})$

All periods of time reported during the day are expressed as absolute time and $\%$ of the total awake time.

\section{Measurements}

Demographics, anthropometrics, level of education and employment were recorded in both patients and controls;

In patients, the following data were recorded or assessed:

- Global initiative for chronic obstructive lung disease (GOLD) stages [15], and reported number and severity of exacerbations in the previous 12 months;

- Static and dynamic lung volumes by means of a body plethysmograph according to the American Thoracic Society [16], using the predicted values of the European Respiratory Society [17];

- Arterial blood gases by means of automatic analyzers on samples from the radial artery with the patient in sitting position, breathing room air;

- Subjective sensation of dyspnea by means of the modified Medical Research Council (mMRC) scale [18];

- Exercise tolerance assessed by means of the 6MWD according to accepted guidelines [19]: the predicted values were by 
Enright and Sherrill [20]. At the beginning and at the end of walking, subjective sensations of dyspnea and leg fatigue were assessed by means of a modified Borg scale [21];

- Symptoms burden on health status by the COPD Assessment Test (CAT) [22];

- The composite and multi-dimensional body-mass index, airflow obstruction, dyspnea, and exercise capacity (BODE) index [23].

\section{Statistical analysis}

The effect size for the correlation between MaDA and measured parameters was expected medium to high $(\mathrm{r} \sim 0.4)$. In order to detect departure from the hypothesis (i.e. small effect size, $\mathrm{r}<$ 1), the required sample size involved at least 60 subjects (alpha $=$ 0.05 , beta $=0.8$, one sided test).

Descriptive statistics were performed reporting means and standard deviations [mean (SD)] for continuous variables, numbers (n) and percentages (\%) for categorical variables. Student's ttest for non-paired values was used to compare the means of groups for quantitative variables. For categorical variables, the Chi-squared test or Fisher's exact test, if necessary, was employed.

Student T test was used to compare ST and AT, duration and percentage of ACT and SET differences between healthy subjects and patients. ANOVA test was used to assess differences among GOLD stages.

The relationship between the percentage of time spent in activities (\%ACT) as estimated by MaDA and patients' clinical status and conditions was investigated using Spearman's rank correlation for ordinal data (GOLD stages, CAT, mMRC, Bode Index) and linear correlation for continuous variables.

The data were analyzed by using StataCorp Stata 13.1 software.

\section{Results}

The selection procedure is shown in Figure 2. Sixty patients and 60 healthy subjects were enrolled and answered the question- naire. Thirty-six patients and controls were enrolled at Tradate, 14 at Lumezzane, and 10 at Novaggio.

Characteristics of patients and controls are shown in Table 1. The only difference between groups was the higher level of education in controls.

Physiological and clinical characteristic of all patients are shown in Table 2. GOLD severity stages 2 and 3 according airway obstruction and groups B and D according to the new classification $^{15}$ accounted for more than $75 \%$ of patients. There was only one potentially relevant difference in physiological parameters among centers (residual volume (RV), \% predicted: $140.8 \pm 51.4$, $187.8 \pm 41.9,152.2 \pm 38.0$ for Tradate, Novaggio and Lumezzane respectively: $\mathrm{p}=0.0291$ ).

The comparison of activity time in patients and healthy subjects is shown in Table 3. As compared with controls, patients spent significantly less time sleeping $(47.3 \pm 9.9$ vs $50.1 \pm 2.1$ hours respectively, $\mathrm{p}=0.03)$ and more time awake $(120.6 \pm 9.9 \mathrm{vs}$ $117.8 \pm 2.0$ hours respectively, $\mathrm{p}=0.03)$ and in sedentary $(49.2 \pm$ 21.0 vs $41.2 \pm 15.7$ hours, respectively, $\mathrm{p}=0.01$ ) behavior. There were no significant differences among GOLD stages either classified on airway obstruction $(\mathrm{p}=0.140)$ or according the new definition $(\mathrm{p}=0.277)$.

Figure 3 shows the values of assessed measures according the time spent in activity, whereas Table 4 shows that ACT but not SET of patients was significantly correlated with mMRC, CAT, Bode Index, 6MWD and Borg fatigue perceived after 6MWD, but not with demographics, anthropometrics or levels of airway obstruction. There was no correlation with education level in any group.

\section{Discussion}

We propose a tool to profile the time of daily activity in patients with COPD. The lack of a simple tool pushed us to evaluate a profiler to be used to address the rehabilitative intervention. Furthermore, as most of the available questionnaires report

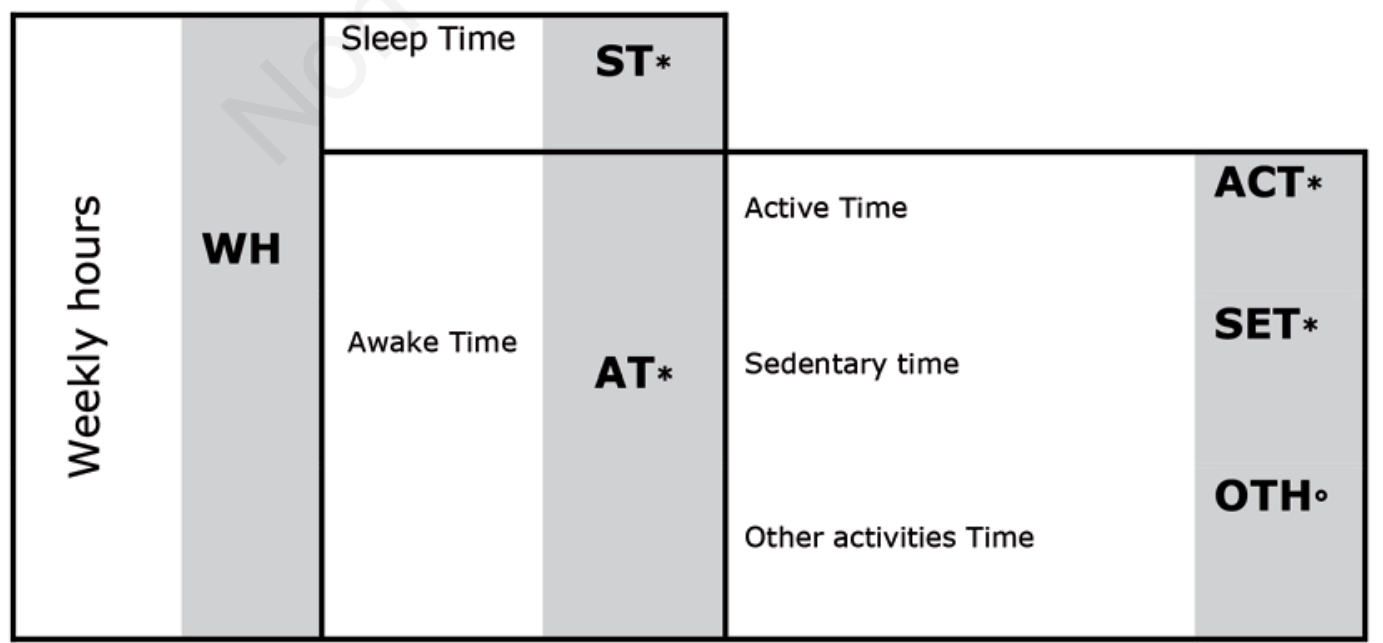

Abbreviations: WH: one week; ST: sleep time; AT: awake time; ACT: active time;

SET: sedentary time; OTH: other time;

* Direct measure, ${ }^{\circ}$ Derived measure

Figure 1. Domains assessed by MaDA. 
the amount of PA, we aimed to develop a tool able to evaluate different periods of activity and time spent in sedentary behavior. Low to moderate correlation observed on country level suggests that cross country comparison is difficult even if the same selfreport instrument is used [24]. Since lifestyles are strongly influenced by medical, environmental, cultural and social conditions, we need instruments specifically tailored to the population under study, in Italian language.

The MaDA profiler revealed that, as compared to healthy controls, patients with COPD spent significantly more time awake and in sedentary behavior. The awake time spent in activities was significantly correlated with levels of dyspnea, symptom burden, exercise capacity but not with the severity of airway obstruction.

No difference was observed between patients with COPD and controls as regards the time spent in PA, while the difference was in the sleeping time and in the time spent in sedentary activities. This lack of difference: it might be due to the self-reported description of the activities performed by the single person. Physical activity, as per definition $[1,2]$, reflects "what a patient is actually doing", whereas exercise capacity, is a measure of

Table 1. Demographics and social data.

\begin{tabular}{|c|c|c|c|c|}
\hline \multicolumn{2}{|l|}{ Variables } & COPD & Controls & p \\
\hline \multicolumn{2}{|l|}{$\mathrm{N}$} & 60 & 60 & - \\
\hline \multicolumn{2}{|l|}{ Male, n (\%) } & $38(63.3)$ & $39(65)$ & 0.849 \\
\hline \multicolumn{2}{|l|}{ Age, years } & $70.5 \pm 7.3$ & $71.2 \pm 7.1$ & 0.293 \\
\hline \multicolumn{2}{|c|}{ Subjects with walking problems, $\mathrm{n}(\%)$} & $12(20.0)$ & $17(28.3)$ & 0.286 \\
\hline \multicolumn{2}{|c|}{ Subjects use of walking device, $\mathrm{n}(\%)$} & $3(5.0)$ & $6(10.7)$ & 0.298 \\
\hline Educational level, n (\%) & $\begin{array}{l}\text { None } \\
\text { Primary school } \\
\text { Secondary school } \\
\text { High school } \\
\text { University }\end{array}$ & $\begin{array}{l}1(1.67) \\
20(33.3) \\
24(40.0) \\
11(18.3) \\
4(6.7)\end{array}$ & $\begin{array}{l}- \\
12(20.1) \\
14(23.3) \\
17(28.3) \\
17(28.3)\end{array}$ & 0.005 \\
\hline Marital status, n (\%) & $\begin{array}{l}\text { Married } \\
\text { Divorced } \\
\text { Widow/er } \\
\text { Single }\end{array}$ & $\begin{array}{c}37(61.7) \\
6(10.0) \\
10(16.7) \\
7(11.6)\end{array}$ & $\begin{array}{c}49(81.6) \\
4(6.7) \\
4(6.7) \\
3(5)\end{array}$ & 0.100 \\
\hline Employment, n (\%) & $\begin{array}{l}\text { Employed } \\
\text { Never employed/housewife } \\
\text { Retired } \\
\text { Invalid } \\
\text { Unemployed, at present }\end{array}$ & $\begin{array}{c}6(10.0) \\
5(8.4) \\
47(78.4) \\
1(1.6) \\
1(1.6)\end{array}$ & $\begin{array}{c}6(10.0) \\
8(13.3) \\
44(73.3) \\
- \\
2(3.4)\end{array}$ & 0.698 \\
\hline Living, n (\%) & $\begin{array}{l}\text { Alone } \\
\text { With other }\end{array}$ & $\begin{array}{l}15(25) \\
45(75)\end{array}$ & $\begin{array}{c}6(10.0) \\
54(90.0)\end{array}$ & 0.111 \\
\hline
\end{tabular}

COPD, chronic obstructive pulmonary disease.

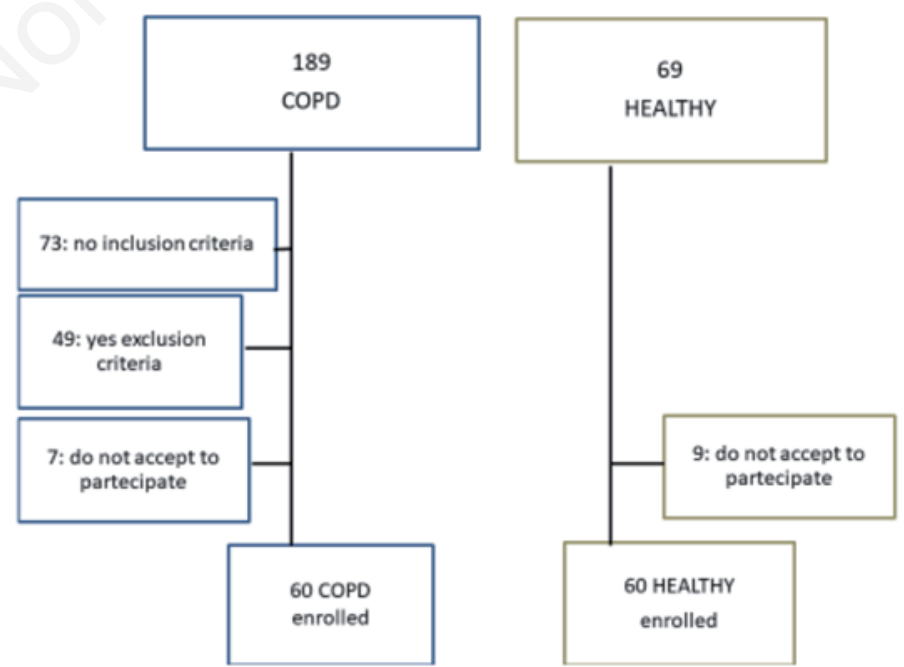

COPD: chronic obstructive pulmonary disease.

Figure 2. Selection procedure. 
"what a patient can do". Publications about tools for measurement of PA in patients with COPD has increased exponentially since Pitta et al. reported the first characterization of the PA of these patients using an objective measurement [25]. Multiple questionnaires exist to measure PA. A systematic review concluded that there were 104 different questionnaires available to measure PA or related constructs in elderly or chronically ill populations [26]. From the questionnaires identified in this systematic review, 15 were developed for patients with COPD. Validity was assessed in $85 \%$ of these instruments, test-retest-reliability in $69 \%$ and responsiveness in only $19 \%$, and none of the instruments was based on a conceptual framework [27]. Several questionnaires have been included in validation studies in patients with COPD [28-33], in comparison with activity monitoring. In general, the accuracy of questionnaires to estimate the individual PA of a patient is poor, nevertheless, because they are able to identify extremes in PA they can be used in large epidemiological studies. The accuracy of using self-report is influenced by overestimation of the PA [34], recall bias and tendency to provide socially desirable information. Questionnaires used to measure symptoms and health status containing a domain related to PA cannot be used for an individual measure of PA [35].

The only difference between characteristics of patients and controls of our study was the higher level of education in healthy subjects, which is unlikely to have influenced differences in answers, as the time spent in activity showed no correlation with education level in either group. Residual volume was the only significant difference in physiological data among center. We are confident that this difference has not influenced results as the prevalence in GOLD stages either classified on airway obstruction or according the new definition was not different.
As compared with controls, patients spent significantly more time awake and in sedentary behavior. In the general adult population, sleep disorder symptoms increase with age and usually are greater in women. Furthermore, there is an increased prevalence of sleep symptoms among patients with COPD [36]. Chronic obstructive pulmonary disease is frequently associated with sleep-related breathing disorders, including sleep-related hypoxemia, obstructive sleep apnea, central sleep apnea, respiratory effort-related arousals, and sleep-related hypoventilation. These sleep-related breathing disorders may be associated with nonrestorative sleep and daytime sleepiness and fatigue and reduced exercise capacity $[37,38]$.

The time spent in activities of our patients was significantly correlated with dyspnea, as assessed by mMRC, with symptom burden as assessed by the CAT, with Bode Index, and with exercise capacity as assessed by means of 6MWD, but not with levels of airway obstruction. These results confirm those by Pitta et al. obtained with activity monitors [25]. As compared with healthy controls, patients in the Pitta et al. study showed lower walking time, standing time, and movement intensity during walking, as well as higher sitting time and lying time. Walking time was highly correlated with the 6MWD and more modestly to maximal exercise capacity, lung function, and muscle force. At difference, a study evaluating PA patterns and clusters in more than 1000 patients with COPD showed that age, body mass index (BMI), dyspnea grade and age, dyspnea and airflow obstruction (ADO) index were associated with PA measures and hourly patterns. Five clusters were identified which accounted for $60 \%$ of variance of the data. The most inactive cluster was characterized by higher BMI, lower $\mathrm{FEV}_{1}$, worse dyspnea and higher ADO index compared to other clusters [35].
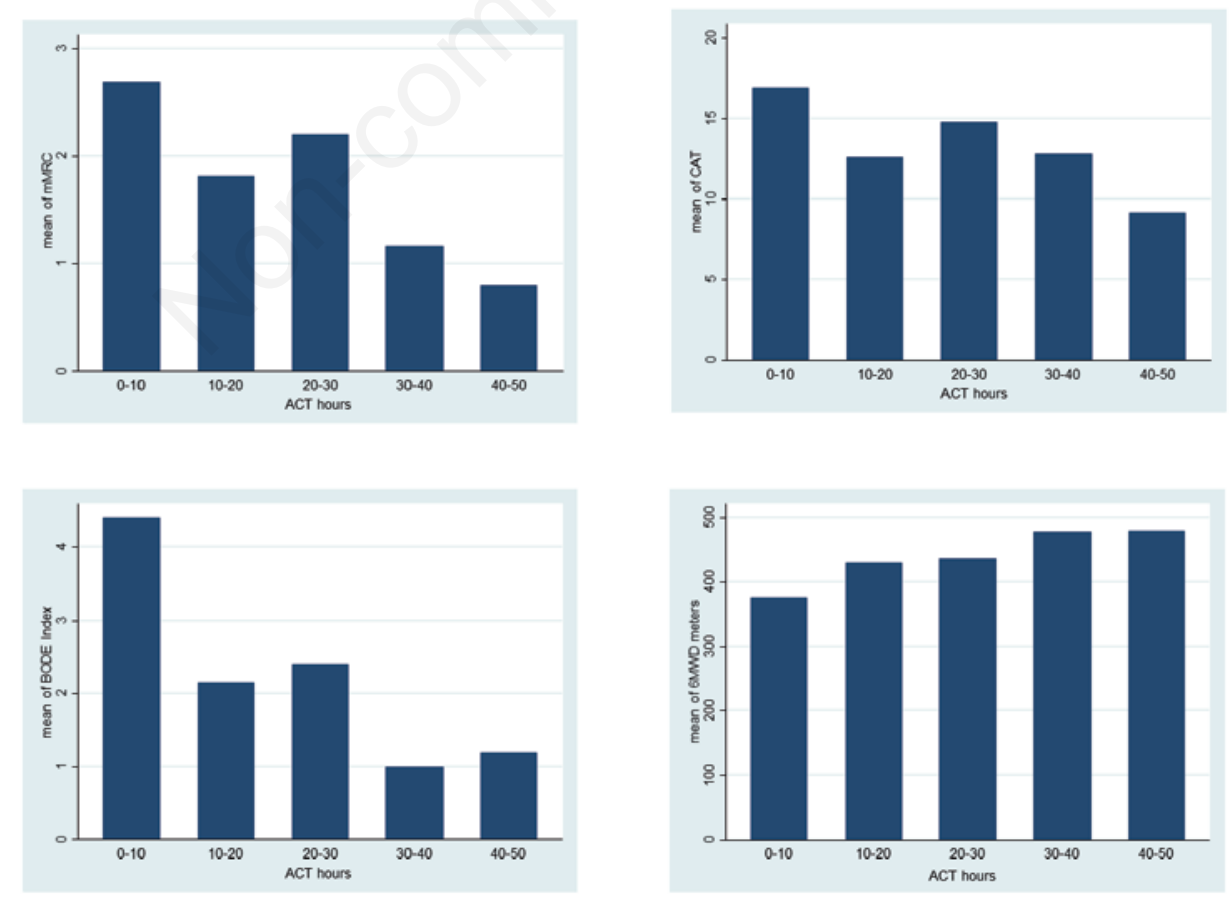

Abbreviations: mMRC: modified Medical Research Council; CAT: COPD Assessment Test; BODE Index: the body-mass, airflow obstruction, dyspnea, exercise index; 6MWD: six minutes walking test.

Figure 3. Values of assessed measures according to time spent in activity. 
Table 2. Anthropometrics, physiological and clinical characteristics of patients with chronic obstructive pulmonary disease.

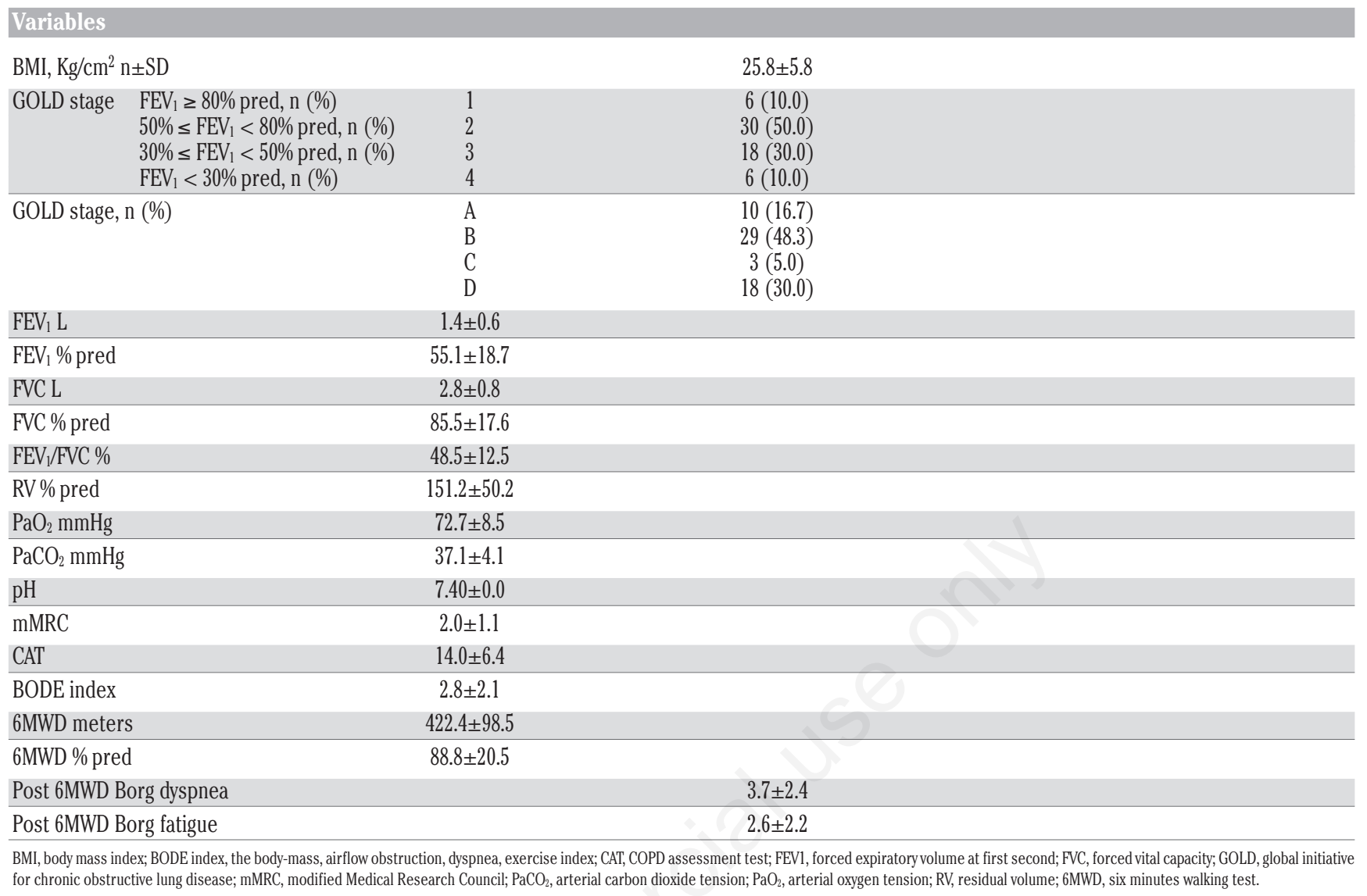

Table 3. Comparison of activity time between patients and healthy subjects.

\begin{tabular}{|c|c|c|c|c|}
\hline & & $\begin{array}{l}\text { COPD } \\
n=60\end{array}$ & $\begin{array}{c}\text { Controls } \\
n=60\end{array}$ & p \\
\hline $\begin{array}{l}\text { ST } \\
\text { AT } \\
\text { ACT } \\
\text { SET } \\
\text { OTH }\end{array}$ & hours & $\begin{array}{c}47.3 \pm 9.9 \\
120.6 \pm 9.9 \\
18.2 \pm 15.8 \\
49.2 \pm 20.9 \\
53.1 \pm 25.7\end{array}$ & $\begin{array}{c}50.1 \pm 2.0 \\
117.8 \pm 2.0 \\
18.5 \pm 13.4 \\
41.2 \pm 15.7 \\
58.0 \pm 20.0\end{array}$ & $\begin{array}{l}0.03 \\
0.03 \\
0.93 \\
0.01 \\
0.25\end{array}$ \\
\hline $\begin{array}{l}\text { \%ACT } \\
\text { \%SET } \\
\text { \%OTH }\end{array}$ & $\% \mathrm{AT}$ & $\begin{array}{l}15.0 \pm 13.2 \\
40.1 \pm 15.7 \\
44.9 \pm 20.1\end{array}$ & $\begin{array}{l}15.7 \pm 11.4 \\
35.1 \pm 13.4 \\
49.2 \pm 17.0\end{array}$ & $\begin{array}{l}0.25 \\
0.03 \\
0.21\end{array}$ \\
\hline
\end{tabular}

ACT, active time; AT, awake time; COPD, chronic obstructive pulmonary disease; OTH, other time; \%ACT, percent of active time; \%AT, percent of awake time; \%0TH, percent of other time; \%SET, percent of sedentary time; SET, sedentary time; ST, sleep time.

Table 4. Correlation between active time (ACT) and sedentary time (SET), expressed as mean time (hours) or percentage, and clinicallfunctional parameters; a) for ordinal and b) for continuous parameters, in chronic obstructive pulmonary disease (COPD) subjects. $\rho$, Spearman's rank correlation coefficient; $R$, Pearson correlation coefficient.

\begin{tabular}{|c|c|c|c|c|c|c|c|c|c|c|c|c|}
\hline \multirow[t]{2}{*}{ a) } & \multicolumn{2}{|c|}{$\mathrm{ACT}$} & \multicolumn{2}{|c|}{ SET } & \multicolumn{2}{|c|}{$\% \mathrm{ACT}$} & \multicolumn{2}{|c|}{$\%$ SET } & & & & \\
\hline & $\rho$ & p & $\rho$ & p & $\rho$ & p & $\rho$ & p & & & & \\
\hline mMRC & -0.51 & 0.000 & 0.01 & 0.96 & -0.51 & 0.001 & 0.03 & 0.83 & & & & \\
\hline CAT & -0.34 & 0.009 & 0.09 & 0.50 & -0.36 & 0.006 & 0.06 & 0.69 & & & & \\
\hline BODE index & -0.54 & 0.000 & 0.06 & 0.64 & -0.55 & 0.001 & 0.07 & 0.60 & & & & \\
\hline b) & $R^{2}$ & $\begin{array}{l}\text { ACT } \\
\text { Coef. }\end{array}$ & p & $R^{2}$ & $\begin{array}{l}\text { SET } \\
\text { Coef. }\end{array}$ & p & $R^{2}$ & $\begin{array}{l}\% A C T \\
\text { Coef. }\end{array}$ & p & $R^{2}$ & $\begin{array}{l}\text { \%SET } \\
\text { Coef. }\end{array}$ & p \\
\hline 6MWD meters & 0.174 & 2.605 & 0.001 & 0.049 & -1.042 & 0.089 & 0.161 & 2.984 & 0.001 & 0.041 & -1.263 & 0.123 \\
\hline 6MWD \% pred & 0.144 & 0.494 & 0.003 & 0.007 & -0.084 & 0.516 & 0.147 & 0.594 & 0.003 & 0.002 & -0.053 & 0.757 \\
\hline Post 6MWD Borg fatigue & 0.171 & -0.058 & 0.001 & 0.003 & 0.006 & 0.686 & 0.158 & -0.067 & 0.002 & 0.004 & 0.009 & 0.648 \\
\hline
\end{tabular}

ACT, active time; BODE index, the body-mass, airflow obstruction, dyspnea, exercise index; CAT, COPD assessment test; mMRC, modified Medical Research Council; \%ACT, percent of active time; \%SET, percent of sedentary time; SET, sedentary time; 6MWD, six minutes walking distance. 
It has been reported that using different questionnaires shifts the patient distribution and results in different clinical characteristics, including PA [39]. In our study ACT was inversely correlated with measures such as CAT and mMRC. The CAT measures the impact of COPD on health status ${ }^{22}$, a score $\geq 10$ is defined as having "high" symptoms in the GOLD strategy. The mMRC assesses the disability due to breathlessness [18], where an mMRC grade $\geq$ 2 points indicates having "high" symptoms. Our results on mMRC are in line with those by Hayata et al. [40].

We did not find any significant correlation of SET with levels of airway obstruction and there were no significant differences in assessed periods among GOLD stages. This may be due to the fact that patients were not evenly distributed among all stages but were concentrated in stages 2 and 3 or B and D. According to other studies, the GOLD classification showed a gradual but substantially overlapping decline in level of PA as assessed by step counters, and accordingly a linear increase in proportion of inactive patients in the more severe levels of airway obstruction [5,39,41], whereas Pitta et al. found only a slight correlation with lung function [25]. Our data confirm those questionnaires and objective measures of activity such as step counters give different information about PA [42]. Also, a study by Paneroni et al. reported that in patients with COPD and chronic hypoxia, daily steps showed a strong correlation with 6MWD, and only a moderate correlation with airway obstruction [43].

\section{Clinical implications}

There is insufficient evidence that incentives to increase PA in patients with a history of COPD exacerbations may affect improvements in acute care use or survival [44], nor the recognized benefits of exercise training do always translate into enhanced PA levels $[8,45]$. However public health guidelines developed for the general population recommend people who have chronic conditions such as COPD, seek advice from health care providers to adequately manage their condition [46], and reducing time spent in sedentary behavior has demonstrated positive effects [47-50]. Therefore, knowledge of patients' behavior profile may be useful in planning individualized self-induced or supported programs of changes in lifestyle. However we did not find any cut-off to distinguish active $v s$ non active patients, and the description of the time spent in active and sedentary activities may be only suggestive of some potential interventions.

\section{Limitations of the study}

Results of MaDA were neither compared with those of objective measurements of activity such as step counters, or of a specific assessment for the cognitive capacity, or test-retest-reliability and responsiveness were assessed. Self-report measures of sedentary time may have resulted in large bias, poor precision and low correlation with an objective measure of sedentary time [47]. The MaDA would be maybe difficult to be self-administered to elderly people with mild cognitive impairment, which is a frequent condition, especially among patients with chronic diseases. On the other hand, the advantages for using a profiler are the inexpensive and practical use, the easy analysis and fast results and further studies will cover these flaws.

\section{Conclusions}

The MaDA profiler may be a useful aid to distinguish patients with COPD in active and sedentary. However, we did not find any cut-off to distinguish active $v s$ non active patients, and the description of the time spent in active and sedentary activities may be only suggestive of some potential interventions. Nonetheless, using this tool, we found that patients with COPD spend longer time awake and in sedentary behavior, these features make MaDA a suitable tool for the profiling of the PA when a basic evaluation must be performed, without being able to use technological devices (e.g. pedometer, etc.). Further studies on larger sample sizes, comparing the results of MaDA with those of objective measurements of activity and evaluating test-retest-reliability and responsiveness are needed.

\section{References}

1. Caspersen CJ, Powell KE, and Christenson GM. Physical activity, exercise, and physical fitness: definitions and distinctions for health-related research. Public Health Rep 1985;100:126-31.

2. Watz H, Pitta F, Rochester CL, et al. An official European Respiratory Society statement on physical activity in COPD. Eur Respir J 2014;44:1521-37.

3. Lear SA, Hu W, Rangarajan S, et al. The effect of physical activity on mortality and cardiovascular disease in 130000 people from 17 high-income, middle-income, and low-income countries: the PURE study. Lancet 2017;390:2643-54.

4. Leskinen T, Stenholm S, Aalto V, et al. Physical activity level as a predictor of healthy and chronic disease-free life expectancy between ages 50 and 75. Age Ageing 2018;47:423-9.

5. Waschki B, Kirsten AM, Holz O, et al. Disease progression and changes in physical activity in patients with chronic obstructive pulmonary disease. Am J Respir Crit Care Med 2015; 192:295-306.

6. Spruit MA, Singh SJ, Garvey C, et al. An official American Thoracic Society/European Respiratory Society statement: key concepts and advances in pulmonary rehabilitation. Am J Respir Crit Care Med 2013;188:e13-64.

7. Paneroni M, Vitacca M, Venturelli M, et al. The impact of exercise training on fatigue in patients with chronic obstructive pulmonary disease: a systematic review and meta-analysis. Pulmonology 2020;26:304-13.

8. Cindy Ng LW, Mackney J, Jenkins S, Hill K. Does exercise training change physical activity in people with COPD? A systematic review and meta-analysis. Chron Respir Dis 2012;9:17-26.

9. Ambrosino N, Clini EM. Response to pulmonary rehabilitation: toward personalized programmes? Eur Respir J 2015;46:1538-40.

10. Dall PM, Coulter EH, Fitzsimons CF, et al. TAxonomy of Selfreported Sedentary behaviour Tools (TASST) framework for development, comparison and evaluation of self-report tools: content analysis and systematic review. BMJ Open 2017; 7:e013844.

11. Gimeno-Santos E, Raste Y, Demeyer H, et al. The PROactive instruments to measure physical activity in patients with chronic obstructive pulmonary disease. Eur Resp J 2015;46:988-1000.

12. Wanner M, Hartmann C, Pestoni G, et al. Validation of the Global Physical Activity Questionnaire for self-administration in a European context. BMJ Open Sport Exerc Med 2017;3:e000206.

13. Stewart AL, Mills KM, King A C, et al. CHAMPS Physical Activity Questionnaire for Older Adults: Outcomes for Interventions. Med Sci Sports Exerc 2001;33:1126-41. 
14. Mokkink LB, Terwee CB, Patrick DL, et al. The COSMIN checklist for assessing the methodological quality of studies on measurement properties of health status measurement instruments: an international Delphi study. Qual Life Res 2010;19:539-49.

15. Global Initiative for Chronic Obstructive Lung Disease (GOLD). Global Strategy for Prevention, Diagnosis and Management of COPD. 2019 Report. 2019. Accessed: April 6, 2020. Available from: http://goldcopd.org/gold-reports/

16. Celli BR, MacNee W, Agusti A, et al. Standards for the diagnosis and treatment of patients with COPD: a summary of the ATS/ERS position paper. Eur Respir J 2004;23:932-46.

17. Pellegrino R, Viegi G, Brusasco V, et al. Interpretative strategies for lung function tests. Eur Respir J 2005;26:948-68.

18. Fletcher CM. Standardised questionnaire on respiratory symptoms: a statement prepared and approved by the MRC Committee on the Aetiology of Chronic Bronchitis (MRC breathlessness score). Br Med J 1960;2:1665.

19. Holland AE, Spruit MA, Troosters T, et al. An official European Society/American Thoracic Society technical standard: field walking tests in chronic respiratory disease. Eur Respir J 2014;44:1428-46.

20. Enright PL, Sherrill DL. Reference equations for the sixminute walk in healthy adults. Am J Respir Crit Care Med 1998;158:1384-7.

21. Borg G. Psychophysical basis of perceived exertion. Med Sci Sports Exerc 1982;14:377-381.

22. Jones PW, Harding G, Berry P, et al. Development and first validation of the COPD Assessment Test. Eur Respir J 2009;34:648-54.

23. Celli BR, Cote CG, Marin JM, et al. The body-mass index, airflow obstruction, dyspnea, and exercise capacity index in chronic obstructive pulmonary disease. N Engl J Med 2004;350:1005-12.

24. Steene-Johannessen J, Anderssen SA, van der Ploeg HP, et al. Are self-report measures able to define individuals as physically active or inactive? Med Sci Sports Exerc 2016;48:235-44.

25. Pitta F, Troosters T, Spruit MA, et al. Characteristics of physical activities in daily life in chronic obstructive pulmonary disease. Am J Respir Crit Care Med 2005;171:972-7.

26. Frei A, Williams K, Vetsch A, et al. A comprehensive systematic review of the development process of 104 patient-reported outcomes (PROs) for physical activity in chronically ill and elderly people. Health Qual Life Outcomes 2011;9:116-28.

27. Gimeno-Santos E, Frei A, Dobbels F, et al. Validity of instruments to measure physical activity may be questionable due to a lack of conceptual frameworks: a systematic review. Health Qual Life Outcomes 2011;9:86-98.

28. Donaire-Gonzalez D, Gimeno-Santos E, Serra I, et al. Validation of the Yale Physical Activity Survey in chronic obstructive pulmonary disease patients. Arch Bronconeumol 2011;47:552-60.

29. Garfield BE, Canavan JL, Smith CJ, et al. Stanford Seven-Day Physical Activity Recall questionnaire in COPD. Eur Respir J 2012;40:356-62.

30. DePew ZS, Garofoli AC, Novotny PJ, Benzo RP. Screening for severe physical inactivity in chronic obstructive pulmonary disease: the value of simple measures and the validation of two physical activity questionnaires. Chron Respir Dis 2013;10:19-27.

31. van Gestel AJ, Clarenbach CF, Stowhas AC, et al. Predicting daily physical activity in patients with chronic obstructive pulmonary disease. PLoS One 2012; 7:e48081.

32. Sievi NA, Brack T, Brutsche MH, et al. Accelerometer- versus questionnaire-based assessment of physical activity and their changes over time in patients with COPD. Int J Chron Obstruct Pulmon Dis 2017;12:1113-1118.

33. Pitta F, Troosters T, Spruit MA, et al. Activity monitoring for assessment of physical activities in daily life in patients with chronic obstructive pulmonary disease. Arch Phys Med Rehabil 2005;86:1979-85.

34. Forsen L, Loland NW, Vuillemin A, et al. Self-administered physical activity questionnaires for the elderly: a systematic review of measurement properties. Sports Med 2010; 40:601-3.

35. Mesquita R, Spina G, Pitta F, et al. Physical activity patterns and clusters in 1001 patients with COPD. Chron Respir Dis 2017;14:256-69.

36. Maestri R, Bruschi C, Fracchia C, et al. Physiological and clinical characteristics of patients with COPD admitted to an inpatient pulmonary rehabilitation program: A real-life study. Pulmonology 2019;25:71-8.

37. Budhiraja R, Siddiqi TA, Quan SF. Sleep disorders in chronic obstructive pulmonary disease: etiology, impact, and management. J Clin Sleep Med 2015;11:259-70.

38. Vitacca M, Paneroni M, Braghiroli A, et al. Exercise capacity and comorbidities in patients with obstructive sleep apnoea. J Clin Sleep Med 2020;15;16:531-8.

39. Demeyer H, Gimeno-Santos E, Rabinovich RA, et al. Physical Activity Characteristics across GOLD Quadrants Depend on the Questionnaire Used. PLoS One 2016;11:e0151255.

40. Hayata A, Minakata Y, Matsunaga K, et al. Differences in physical activity according to mMRC grade in patients with COPD. Int J Chron Obstruct Pulmon Dis 2016;11:2203-8.

41. Shrikrishna D, Patel M, Tanner RJ, et al. Quadriceps wasting and physical inactivity in patients with COPD. Eur Respir J 2012;40:1115-22.

42. Widyastuti K, Makhabah DN, Setijadi AR, et al. Benefits and costs of home pedometer assisted physical activity in patients with COPD. A preliminary randomized controlled trial. Pulmonology 2018;24:211-8.

43. Paneroni M, Ambrosino N, Simonelli C, et al. Physical activity in patients with chronic obstructive pulmonary disease under long term oxygen therapy: a cross-sectional study. Int J Chron Obstruct Pulmon Dis 2019;14:2815-23.

44. Nguyen HQ, Moy ML, Liu IL, et al. Effect of physical activity coaching on acute care and survival among patients with chronic obstructive pulmonary disease. A pragmatic randomized clinical trial. JAMA Netw Open 2019;2:e199657.

45. Santos DC, Santos JA, Santos M, et al. Pulmonary rehabilitation adapted index of self-efficacy (PRAISE) validated to Portuguese respiratory patients. Pulmonology 2019;25:334-9.

46. World Health Organization. Global recommendations on physical activity for health. Accessed: April 7, 2020. Available from: http://whqlibdoc.who.int/publications/2010/9789241599979

47. Chastin SFM, Dontje ML, Skelton DA, et al. Systematic comparative validation of self-report measures of sedentary time against an objective measure of postural sitting (activPAL). Int J Behav Nutr Phys Act 2018:26;15:21.

48. Park SK and Larson JL. The relationship between physical activity and metabolic syndrome in people with chronic obstructive pulmonary disease. J Cardiovasc Nurs 2014;29: 499-507.

49. Gimeno-Santos E, Frei A, Steurer-Stey C, et al. Determinants and outcomes of physical activity in patients with COPD: a systematic review. Thorax 2014;69:731-9.

50. Reid KJ, Baron KG, Lu B, et al. Aerobic exercise improves self-reported sleep and quality of life in older adults with insomnia. Sleep Med 2010;11:934-40. 